Article

\title{
Jasminum sambac: A Potential Candidate for Drug Development to Cure Cardiovascular Ailments
}

\author{
Imran Ahmad Khan ${ }^{1, *}$, Musaddique Hussain ${ }^{1}$, Shaukat Hussain Munawar ${ }^{2}$, Muhammad Omer Iqbal ${ }^{1,3} \mathbb{D}^{\text {, }}$ \\ Shafia Arshad 4(D), Ashira Manzoor ${ }^{5}$, Mazhar Abbas Shah ${ }^{5}$, Khizar Abbas ${ }^{5}$, Waleed Shakeel ${ }^{6}$ \\ and Shahzada Khurram Syed ${ }^{7}$ (D)
}

Citation: Khan, I.A.; Hussain, M.; Munawar, S.H.; Iqbal, M.O.; Arshad, S.; Manzoor, A.; Shah, M.A.; Abbas, K.; Shakeel, W.; Syed, S.K. Jasminum sambac: A Potential Candidate for Drug Development to Cure Cardiovascular Ailments. Molecules 2021, 26, 5664. https://doi.org/ $10.3390 /$ molecules 26185664

Academic Editors: Gianluca Paventi, Giuseppe Rotundo and Giacinto S. Germinara

Received: 17 August 2021

Accepted: 13 September 2021

Published: 18 September 2021

Publisher's Note: MDPI stays neutral with regard to jurisdictional claims in published maps and institutional affiliations.

Copyright: (c) 2021 by the authors. Licensee MDPI, Basel, Switzerland. This article is an open access article distributed under the terms and conditions of the Creative Commons Attribution (CC BY) license (https:/ / creativecommons.org/licenses/by/ $4.0 /)$.
1 Department of Pharmacology, The Islamia University of Bahawalpur, Bahwalpur 63100, Pakistan; musaddique.hussain@iub.edu.pk (M.H.); oiqbal133@gmail.com (M.O.I.)

2 Department of Pharmacology and Toxicology, Cholistan University of Veterinary and Animal Sciences, Bahawalpur 63100, Pakistan; shaukathussainmunawar@cuvas.edu.pk

3 Key Laboratories of Marine Drugs (Ministry of Education), Shandong Laboratory of Glycoscience and Glycoengineering, School of Pharmacy, Ocean University of China, Qingdao 266100, China

4 Faculty of Medicine and Allied Health Sciences, The Islamia University of Bahawalpur, Bahawalpur 63100, Pakistan; shafia.arshad@iub.edu.pk

5 Fatima Tu Zahara Department of Life Sciences, Muhammad Institute of Medical and Allied Sciences, Multan 60000, Pakistan; ashiramanzoor@gmail.com (A.M.); mazharshah558@gmail.com (M.A.S.); khizarabbasbhutta786@gmail.com (K.A.)

6 Department of Pharmacology, Bahauddin Zakariya University, Multan 60000, Pakistan; waleed.shakeel@yahoo.com

7 Department of Basic Medical Sciences, School of Health Sciences, University of Management and Technology, Lahore 54770, Pakistan; shahzada.khurram@umt.edu.pk

* Correspondence: imranahmadkhandurrani@gmail.com; Tel.: +92-3336120602

\begin{abstract}
Jasminum sambac (L.) is a South Asian folkloric medicinal plant that has traditionally been used to treat cardiovascular problems. The current investigation was meticulously organized to explore the pharmacological foundation for the medicinal uses of J. sambac pertaining to cardiovascular ailments and to investigate the core mechanisms. Mechanistic investigation revealed that crude leaf extract of $J$. sambac produced ex-vivo vasorelaxant effects in endotheliumintact aorta ring preparation and hypotensive effect was recorded via pressure and force transducers coupled to the Power Lab Data Acquisition System. Moreover; J. sambac showed cardioprotective effects against adrenaline -induced left ventricular hypertrophy in rabbits observed hemodynamic. CK-MB, LDH, troponin, CRP, ALT, AST, ALP levels were shown to be lower in the myocardial infarction model, as were necrosis, oedema, and inflammatory cell recruitment in comparison to control. J. sambac has shown good antioxidant potential as well as prolonged the noradrenaline induced platelet adhesion. The vasorelaxant and cardioprotective effects in both in vivo and ex vivo experiments, which are enabled by activation of muscarinic receptor and/or releasing the nitric oxide and by reducing the adrenaline, induced oxidative stress, justifying its usage in cardiovascular disorders.
\end{abstract}

Keywords: adrenaline; cardioprotective; CK-MB; AST; ALT; CRP

\section{Introduction}

Myocardial infarction is the leading cause of death in humans in many developed countries [1]. Because of the changing lifestyle patterns in many developing countries such as Pakistan, India, Bangladesh, and Afghanistan are rapidly catching up with this epidemic at an alarming rate [1]. Though synthetic medicines are very useful in the treatment of cardiovascular ailments their use is restricted due to their harmful effects [2,3]. Myocardial infarction is a serious ischemic situation in which extreme necrosis of myocardial tissue takes place. It happens because of the imbalance between blood supply and oxygen requirement of the cardiac muscles $[4,5]$. 
Adrenaline (ADR) is a catecholamine synthesized in the adrenal medulla. Adrenaline is a non-selective agonist of all adrenergic receptors consisting of alpha, beta and their subtypes primarily located on the cardiovascular system [6]. It causes myocardial infarction above the therapeutic dose ( $2 \mathrm{mg} / \mathrm{kg}$ body weight) [6]. This method is applied to induce myocardial infarction in the experimental animal to evaluate the cardioprotective effect of test drugs. It causes myocardial infarction because of lipid peroxidation that leads to the depletion of cellular antioxidants. It causes the overproduction of nitrosative derivatives oxidative stress occurs due to the overproduction of ROS [7]. It increases the $\mathrm{Ca}^{++}$influx by opening the calcium channels of cardiomyocytes, increases oxidative stress by increasing the workload [8]. In a higher dose, it causes aortic and coronary vasoconstriction. It also promotes blood coagulation by increasing the level of clotting factor VIII, fibrinolysis as well as platelet count [9].

The importance of herbal medicines in the treatment of various ailments is invaluable globally. Herbal medicines are continuously providing important therapeutic agents not only in traditional but also in modern medicines and also because they are less toxic than synthetic medicines [3,5].

Jasminum sambac (Oleaceae), commonly called Jasmin, phytochemical investigation of $J$. sambac validated the existence of proteins, glycosides, coumarins, flavonoids, phenolics, resin, saponins, steroids, terpenes, ascorbic acid, essential oils and salicylic acid [10]. The dried leaf extract was found rich in quercitrin, quercitrin-3-dirhamnoglycoside, isoquercitrin, rutin, kaempherol-3-rhamnoglycosides, $\beta$-sitisterol, 2, 3-dihydro-benzofuran, $\alpha$-amyrin,2, 6, 10-trimethyl, 1-nonadecene, bicycle-2,2,1-heptane-2,5-diol,14-ethylene-14pentadecne, 1-nonadecene, alpha.-tocopherol-.beta.-d-mannoside, 1-heptacosanol. Jasmintides (jS1 and jS2), a unique plant based cysteine-rich peptides, were isolated from J. sambac, 1-Octadecyne; 1-Octadecyne; hexadecanoic acid, $n$-hexadecenoic acid, hexadecenoic acid, R-limonene, 9- octadecenoic acid, and squalene [11]. Pharmacological studies showed antimicrobial, analgesic, antipyretic, anticancer, antioxidant, antidiabetic, insecticidal, lipid-lowering, anti-obesity and gastroprotective effects [12]. Till now there is no recorded experimental foundation for its utilization as a cardioprotective agent. The present study was to see if hydroalcoholic leaf extract of J. sambac had any cardioprotective properties.

\section{Results}

\subsection{Priliminary Phytochemical Screening}

Preliminary phytochemical screening of $J$. sambac (Leaf) revealed the presence of saponins, coumarins, phenols, and flavonoids while alkaloids, tannins and anthraquinones were not detected during the phytochemical investigation (Table 1).

Table 1. Phytochemical analysis of hydroalcoholic leaf extract of J. sambac.

\begin{tabular}{ccc}
\hline Tests & Observation & Results \\
\hline Alkaloid & no ppt & - \\
Saponins & 1 cm froth & + \\
Tannins & No Light purple & - \\
Anthraquinones & No Pink Colour & - \\
Coumarins & Yellow fluorescence. & + \\
Phenols & Light purple & + \\
Flavonoid & Light yellow colour & ++ \\
\hline$+=$ Present, $++=$ highly present,$-=$ absent.
\end{tabular}

\subsection{HPLC Analysis}

The analysis of High Power Liquid Chromatography (HPLC) revealed so many phytoconstituents in varing concentrations, in which the most prominent phytoconstituents are rutin and isoquercetin (Figure 1). 


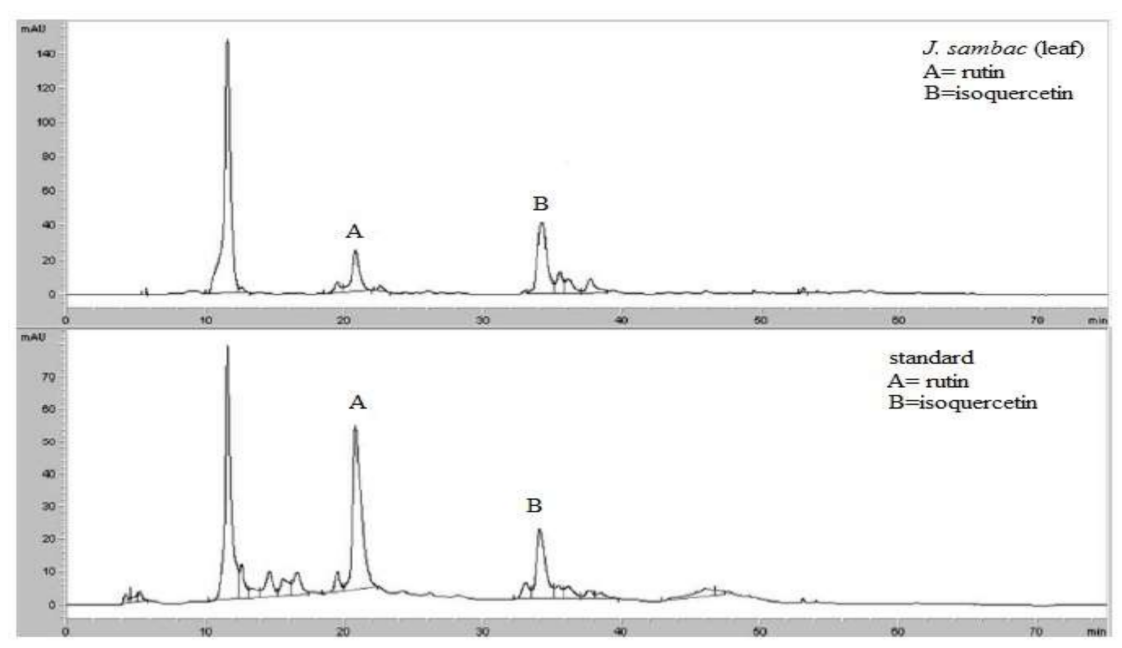

Figure 1. HPLC chromatogram of hydroalcoholic leaf extract of J. samabac showing rutin (A) and isoquercetin (B) similar to standard.

\subsection{DPPH Assay}

In DPPH assay, the inhibitory concentration shown by the hydroalcoholic leaf extract of J. sambac was $120 \mu \mathrm{g} / \mathrm{mL}$ in comparison with ascorbic acid (Figure 2).

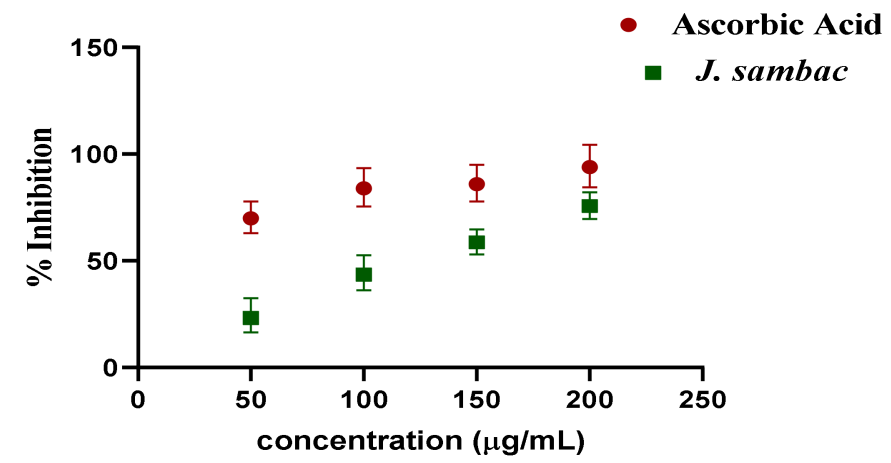

Figure 2. Antioxidant potential of hydroalcoholic leaf extract of J. sambac by DPPH assay.

\subsection{Acute Myocardial Infarction Study}

ADR significantly increased the level of cardiac markers, CK-MB, LDH, troponin, CRP, ALT, AST, ALP $(p<0.05)$ concerning control. ADR group rabbits (group 2$)$ had severe elevated cardiac markers, while the groups treated with the different doses of J. sambac showed resistance against the cardiac damage caused by the ADR in a dose-dependent fashion. In comparison, three groups receiving the leaf extract of J. sambac showed that the average amount of CK-MB, LDH, troponin, CRP, ALT, AST, ALP were reduced $(p<0.05)$ compared to those of the ADR group (Figures 3 and 4). 
(a)

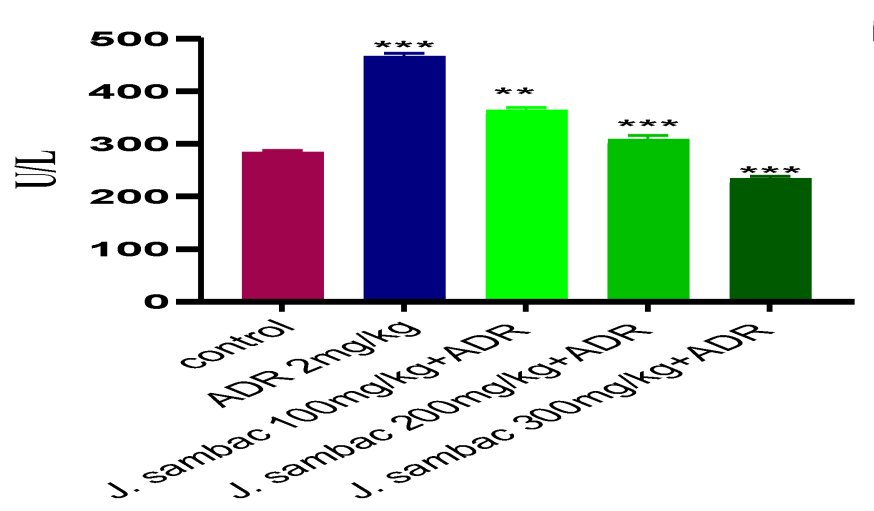

(b)

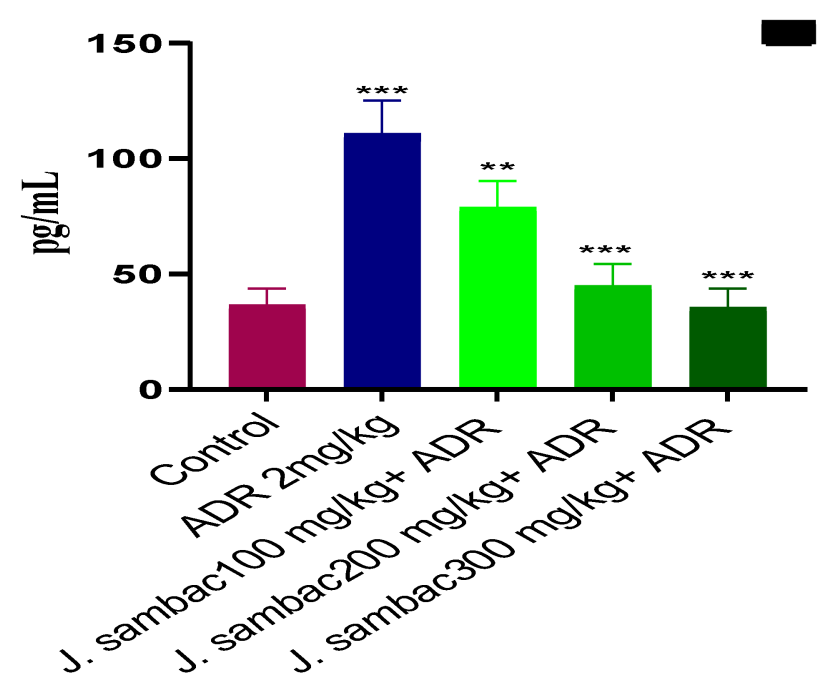

(c)

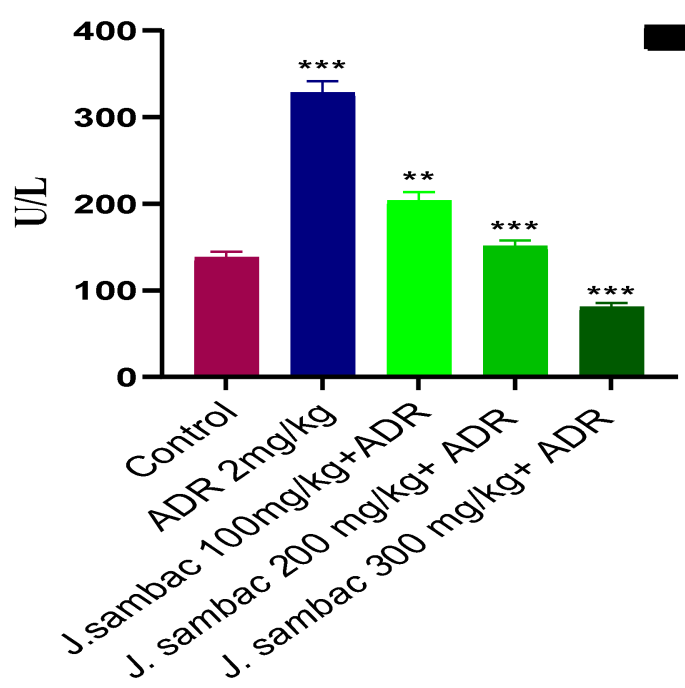

Figure 3. Cardioprotective effect of different doses of J. sambac extracts on the cardiac biomarkers, LDH (a), troponin (b) and CK-MB (c) against ADR-induced myocardial infarction in rabbits. One-way ANOVA was performed for the statistical analysis, comparisons among different groups was carried out by Dunnett's multiple comparison test; ${ }^{* *} p<0.005$ and *** $p<0.0001(n=5)$. 
(a)

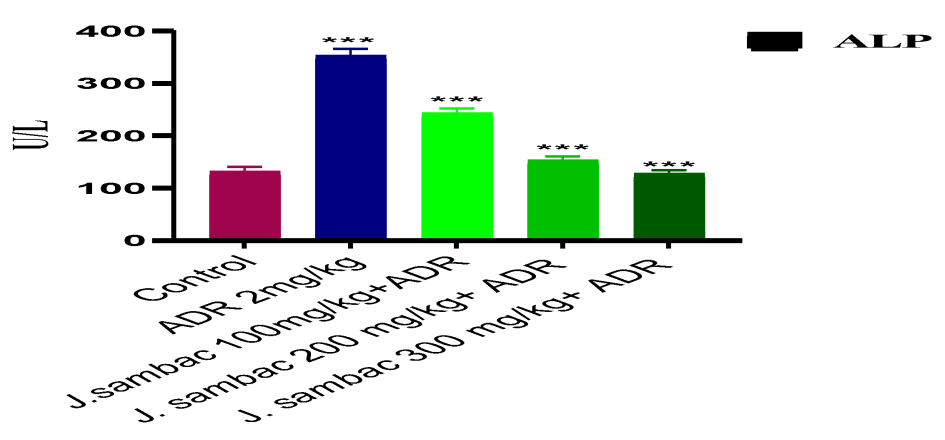

(b)

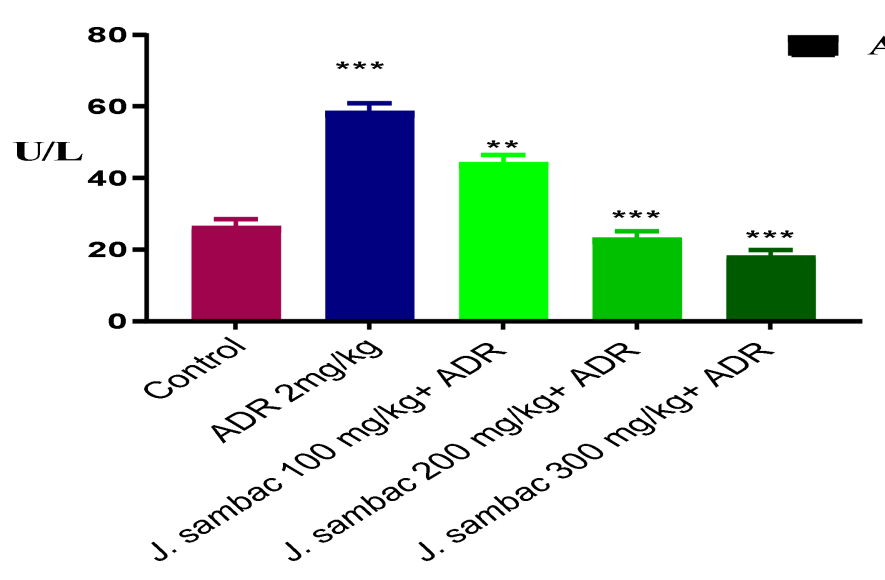

(c)

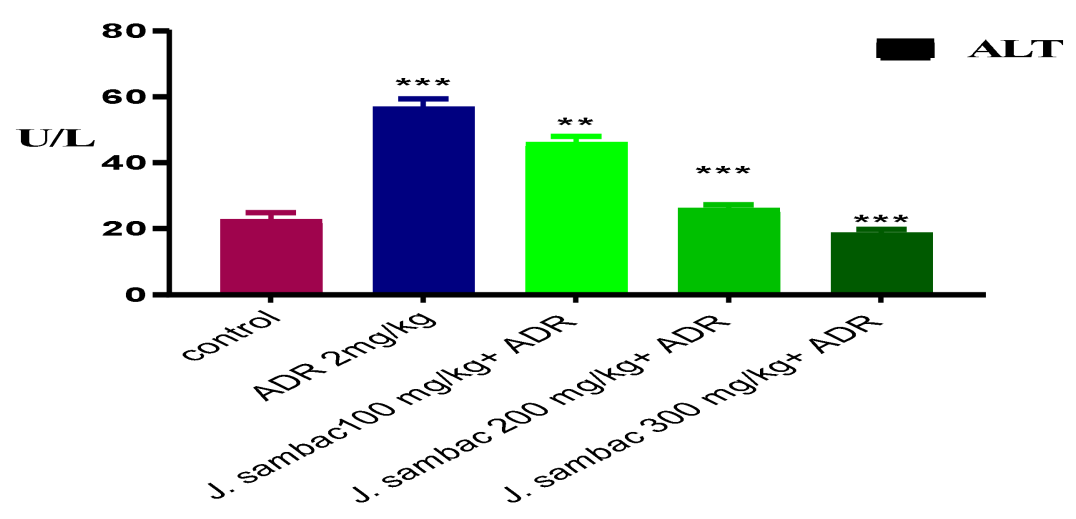

(d)

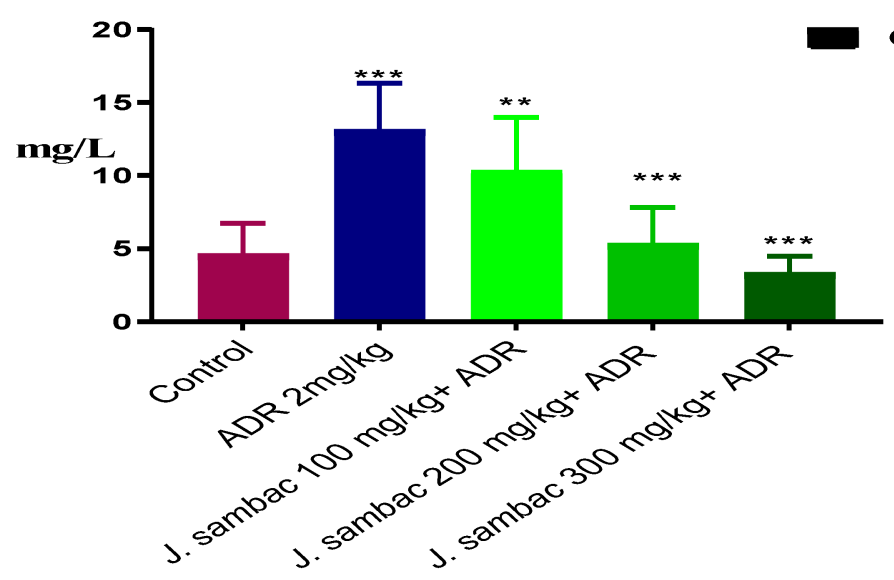

Figure 4. Cardioprotective effect of different doses of J. sambac extracts on the cardiac biomarkers, $\operatorname{ALP}(\mathbf{a})$, AST (b), ALT (c) and CRP (d) against ADR-induced myocardial infarction in rabbits. Oneway ANOVA was performed for the statistical analysis, comparisons among different groups was carried out by Dunnett's multiple comparison test; ${ }^{* *} p<0.005$ and ${ }^{* * *} p<0.0001(n=5)$. 
Effect on Heart to Body Weight, and Weight of Heart to Tail Length Ratios

ADR significantly increased the ratios as compared to the control group. All groups treated with J. sambac were found to reduce the abovementioned ratios less than the ADR treated group (Figure 5).

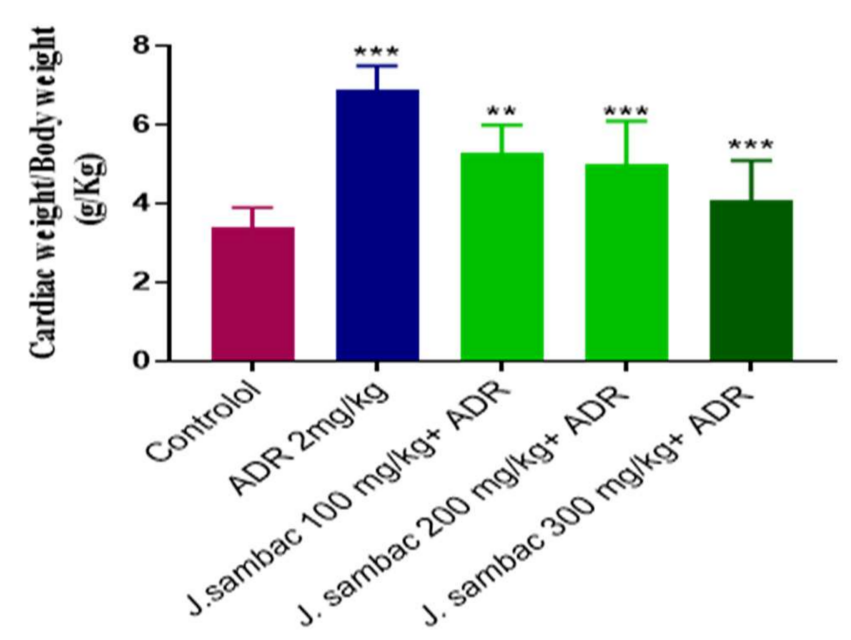

(a)

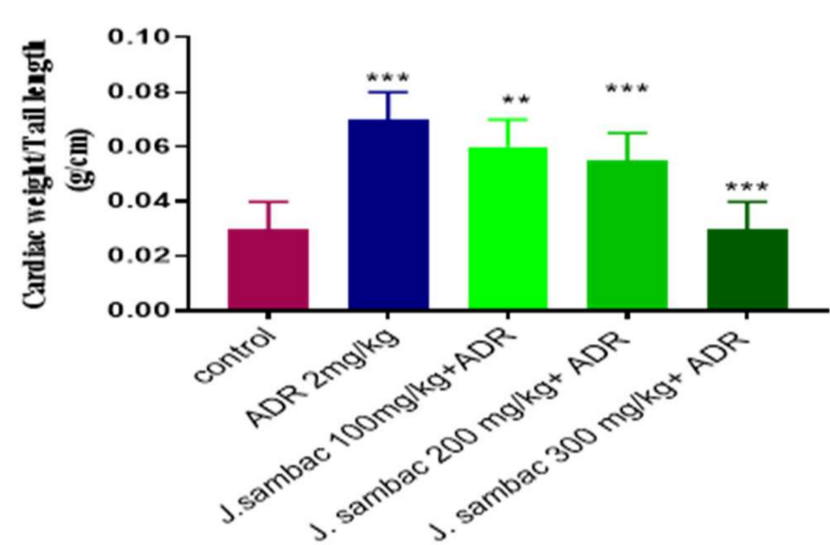

(b)

Figure 5. Cardioprotective effect ofdifferent doses of J. sambac on (a) cardiac weight to body weight ratio and (b) cardiac weight to tail length ratio in ADR-induced cardiac hypertrophied rabbits. One-way ANOVA was performed for the statistical analysis, comparisons among different groups was carried out by Dunnett's multiple comparison test; ${ }^{* *} p<0.005$ and ${ }^{* * *} p<0.0001(n=5)$.

\subsection{Histopathology}

Analysis of segments of heart tissues in the ADR-induced group showed a remarkable change in the cardiac cell structure. In ADR administrated group histological variations for example mononucleate cellular infiltration, interstitial oedema, disintegration and tear of muscular fibers, vacuolar disintegration, distention of capillaries, mottled staining, haemorrhage, and obstruction of the myocardium were observed. Severe necrotic lesions were noticed in all the rabbits while in J. sambac treated groups less myocardial deterioration was observed (Figure 6).

\subsection{Isolated Aortic Tissue Preparation and Vasorelaxant Activity}

Phenylephrine $(1 \mu \mathrm{M})$ caused a contraction in endothelium intact and denuded rabbit aorta. J. samac relaxed completely the endothelium intact aorta at a dose of $3 \mathrm{mg} / \mathrm{mL}$, while at a similar dose, in endothelium-denuded aortic strip no vasodilation was recorded (Figure $7 \mathrm{a})$. Noradrenaline $(10 \mu \mathrm{M})$ caused vasoconstriction in endothelium intact and denuded rabbit aorta, but $J$. sambac produced partial vasodilation in endothelium intact aorta as compared to PE induced contraction at a similar dose while no vasodilatory effect was observed in endothelium-denuded aorta similar to PE induced contractions (Figure $7 \mathrm{~b}$ ). In L- nitro-arginine $\left(1 \times 10^{-4} \mathrm{M}\right)$ and atropine $\left(1 \times 10^{-6} \mathrm{M}\right)$ pretreated aortic strips, the vasodilator effect of $J$. sambac was disappeared at a similar dose (Figure $7 \mathrm{c}, \mathrm{d}$ ). 

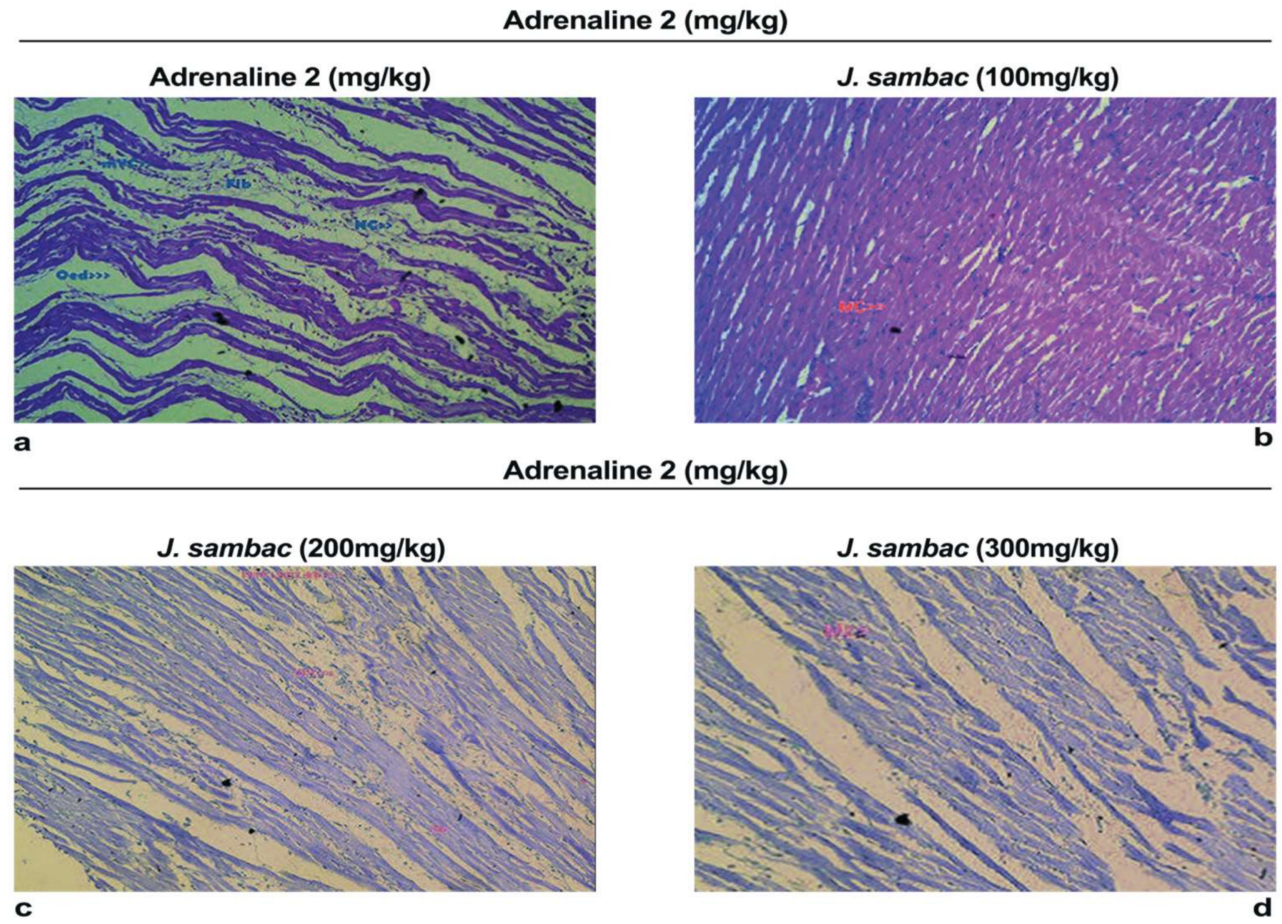

Figure 6. Photomicrographs of rabbit ventricle section from ADR-induced group (a) shows images from ventricle sections received J. sambac $100 \mathrm{mg} / \mathrm{kg}+\mathrm{ADR}$ (b) shows images from ventricle sections received J. sambac $200 \mathrm{mg} / \mathrm{kg}$ (c) Shows ventricle sections received J. sambac $300 \mathrm{mg} / \mathrm{kg}$ + ADR (d). Fewer cardiomyocytes deterioration, fibrosis and less inflammatory cells were observed in dose dependent fashion in comparison with ADR intoxicated group.

(a)

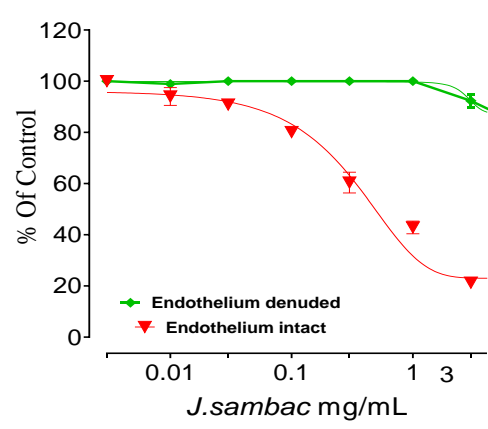

(c)

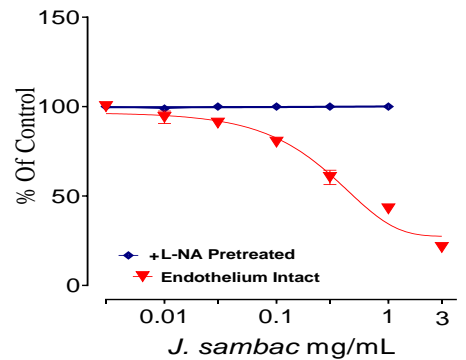

(b)

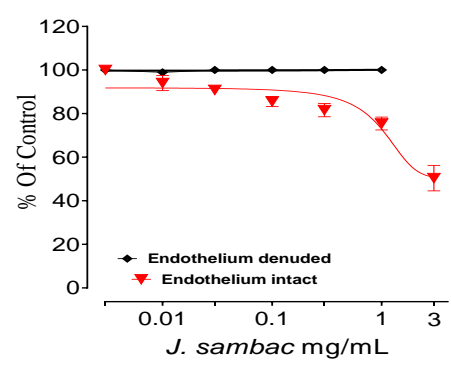

(d)

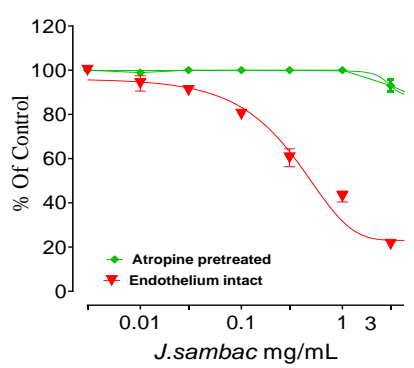

Figure 7. Effect of hydroalcoholic extract J. sambac against $\mathrm{PE}(1 \mu \mathrm{M})$ induced contraction on endothelium intact and denuded aorta (a), noradrenaline $(10 \mu \mathrm{M})$ induced contraction $(\mathbf{b})$, effect against PE $(1 \mu \mathrm{M})$ induced contraction pretreated with L-NA $(\mathbf{c})\left(1 \times 10^{-4} \mathrm{M}\right)$ and $(\mathrm{d})$ atropine $\left(1 \times 10^{-6} \mathrm{M}\right)$. All the values $(n=5)$ are depicted as mean \pm SEM. 


\subsection{Effect on Adrenaline Induced Platelet Activation and Aggregation}

ADR $(2 \mu \mathrm{M})$ addition to the suspension of washed human platelets produced a significant decline in the optical density at $600 \mathrm{~nm}$, indicating the aggregation of platelets. The aggregatory effect was recorded at $37^{\circ} \mathrm{C}$. J. sambac $(100,200$ and $300 \mu \mathrm{g} / \mathrm{mL})$ dramatically inhibited the platelet aggregation (Figure 8) in a dose dependent manner.

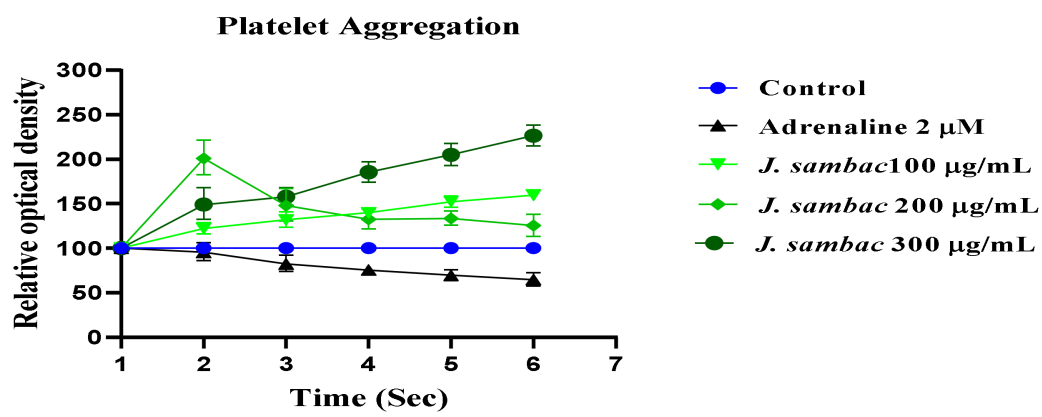

Figure 8. Effect of hydroalcoholic extract of J. sambac on the aggregation of platelet against ADR induced aggregation.

\subsection{Acute Oral Toxicity Dose Test}

No mortality or morbidity was observed at any dose in acute oral toxicity dose test.

\section{Discussion}

As flowers and leaves generally have different phytochemical compositions, the majority of the published data is available on J. sambac flower and its essential oils biological activities [10]. ADR significantly increased the level of cardiac markers, CK-MB, LDH, troponin, CRP, ALT, AST, ALP $(p<0.001)$. In comparison, three groups receiving the leaf extract of J. sambac showed that the average amount of CK-MB, LDH, troponin, CRP, ALT, AST, ALP were reduced compared to those of the intoxicated group which advocates its cardioprotective potential (Figure 2). It was reported that the presence of high amounts of flavonoids in plants was responsible for their cardioprotective potentials $[11,13]$ while, $J$. sambac leaf extract was found rich in flavonoids content (Table 1), [11]. Thus, it is logical to believe that the cardioprotective effect of J. sambac in rabbits might also depend on the presence of these flavonoids.

In the current study, the use of J. sambac hydroalcoholic leaf extract resulted in a significant reduction of CRP in groups receiving the extracts, which may be ascorbic acidor flavonoid-based antioxidant effect of J. sambac (Figure 2) complimenting the previous antioxidant studies $[5,14]$. Saponins are believed to lower the level of lipid peroxidation products in a dose-dependent manner $[15,16]$. The results of this study add to the body of evidence supporting previously published studies on saponins or saponin-containing plant extracts' cardioprotective effects in animal models [17,18]. Similarly J. sambac found richin saponins during phytochemcial evaluation (Table 1).

Early study [19] reported significant LPO inhibitory effect of hydroalcoholic leaf extract of J. sambac which further strengthens its claim as a cardioprotective agent as LPO is one of the major contributory factors in ADR induced MI [20].

Histopathology of heart tissues in the ADR-induced group showed remarkable damage in cardiac cell architecture for example; mononucleate cellular infiltration, interstitial oedema, disintegration and tear of muscular fibers, vacuolar disintegration, and distention of capillaries, mottled staining, haemorrhage, and obstruction of the myocardium were observed. Severe necrotic lesions were noticed in all the rabbits' cardiac tissues but in J. sambac treated groups less myocardial deterioration was observed (Figure 6) which complements the results obtained from the biochemical investigation (Figures 3 and 4). Less inflammatory cells were observed as compared with ADR intoxicated group which is evidence to its cardioprotective effect as reported in previous studies [21]. 
ADR increases the $\mathrm{Ca}^{++}$influx by opening the calcium channels of cardiomyocytes, increases oxidative stress by increasing the workload [6]. A higher dose $(2 \mathrm{mg} / \mathrm{kg}$ body weight), causes aortic and coronary vasoconstriction [6]. PE $(1 \mu \mathrm{M})$ and noradrenaline $(10 \mu \mathrm{M})$ causes vasoconstriction and increases the mean blood pressure primarily by stimulating the alpha-adrenergic receptor and/or opening of voltage-gated L-type calcium channels [22] which in turn increases oxidative stress (Figure 7). The vasodilator effect of $J$. sambac may depend on muscarinic receptor activation or release of cellular vasodilator nitric oxide because the vasodilatory effect was endothelium dependent and completely blocked when pretreated with atropine $\left(1 \times 10^{-6} \mathrm{M}\right)$ and L- NA $\left(1 \times 10^{-4} \mathrm{M}\right)$ like endothelium-denuded aorta (Figure 7). While partial vasodilator effect was observed against noradrenaline $(10 \mu \mathrm{M})$-induced aortic contractions, suggests the involvement of multiple pathways in its vasodilator effect [23]. Flavonoids-based vasodilator effect was reported in the plants earlier [24,25]. J. sambac found rich in flavonoid content (Table 1, Figure 1). Antithrombotic and anticoagulant drugs are well known source of cardioprotection in modern-day cardiology and ADR is a well-established procoagulant [6]. J. sambac significantly reduced the platelet aggregatory effect of ADR [Figure 8] which adds another colour to its cardioprotective potential.

\section{Materials and Methods}

\subsection{Plant Materials}

J. sambac had been collected fresh from Multan. It was authenticated by an expert botanist at the Institute of Pure and Applied Biology, BZ, University, Multan. The voucher specimen (R.R. Stewart, F.W. Pak. 549) has been placed for further reference.

\subsection{Extract Preparation}

The fresh plant was subjected to shade dry. All the foreign adulterants and vegetative waste were eliminated through manual picking before grinding the leaf part of the plant into a coarse powder with the assistance of a special herbal grinder. The crushed plant powder is stored in airtight jars waiting for extraction. The powder attained from only one batch was used in the experiment. J. sambac $(250 \mathrm{~g})$ leaf powder was soaking in a hydroalcoholic solvent $(70: 30 \mathrm{v} / \mathrm{v})$ for 9 days in $2.5 \mathrm{~L}$ amber coloured air-tight jars. Then it was filtered and the filtrate was evaporated at $37^{\circ} \mathrm{C}$ under reduced pressure on a rotatory evaporator to obtain a thick paste-like consistency [26]. At the end \%age yield of the crude extract was calculated using this formula;

$$
\% \text { age yield }=\text { Theoretical yield }(\mathrm{gm}) / \text { Actual yield }(\mathrm{gm}) \times 100
$$

\subsection{Animals}

Male rabbits weighing 1-1.5 $\mathrm{kg}$ had been obtained from the animal house of the Faculty of Pharmacy, The Islamia University of Bahawalpur. They had been nourished with standard commercially available food and tap water ad libitum. The temperature was maintained at $25^{\circ} \mathrm{C}$. The experiments were performed according to the rules of the National Institute of Health [27] and approved by the Ethical Committee of the Department of Pharmacology, The Islamia University of Bahawalpur, Pakistan (BOS \& BOF/10/6/20).

\subsection{Chemicals}

Adrenaline, methanol, phenylephrine, and potassium chloride were purchased from Sigma-Aldrich, St. Louis, MO, USA. Verapamil was purchased from Searle Lahore, PB, Pakistan (PVT.) Ltd. (Lahore, Pakistan) AST, ALP, ALT, LDH, CRP Kits obtained from GM Chemicals and Diagnostics, Multan, PB, Pakistan. All other chemicals utilized the experiment were of highest purity and of reagent analytical grade. 


\subsection{Preliminary Phytochemical Evaluation}

Phytochemical evaluation was done for the validation of various phytochemical classes (alkaloids, anthraquinones, glycosides, tannins, flavonoids and saponins) in the hydroalcoholic extract of J. sambac by using the standard protocol [28].

\subsection{HPLC Analysis}

Phytochemical compounds were separated by using the Agilent HPLC (Santa Clara, CA, USA) sequence 1100 system provided with autosampler, UV/vis detector, quaternary pump, $5 \mathrm{um}, 250 \mathrm{~mm} \times 4.6 \mathrm{~mm}$ i.d. and C18 reversed-phase column (Thermo Electron Corporation, Waltham, MA, USA) connect to HPChemStation software [29]. An (acetic acidwater, 2:98, $v / v$ ) and $B$ (water-acetic acid, 2:98, $v / v$ ) were the solvents used to create the mobile phase (methanol). The following elution scenarios were used: $0-2 \mathrm{~min}, 5$ percent B isocratic; 2-7 min, 5-25 percent B linear gradient; 7-11 min, 25 percent $B$ isocratic; 11-19 min, 25-32 percent B linear gradient; $19-27 \mathrm{~min}, 32$ percent $B$ isocratic; $27-28 \mathrm{~min}$, $32-40$ percent B linear gradient; $28-38$ min, 40 percent B isocratic. The solvents used to create the mobile phase, as well as the column's cleaning and reconditioning procedures (38-50 min, linear gradient $40-100$ percent $B ; 50-60 \mathrm{~min}, 100$ percent $B$ isocratic; $60-70 \mathrm{~min}$, linear gradient $100-5$ percent $B$; and $5 \mathrm{~min}, 5$ percent $B$ (isocratic). The prominent flavonoids in J. sambac leaves, rutin, and quercetin 3-d-glucoside were found had the following standardization curve:

$$
\begin{aligned}
& A=54,252 C-100.12 \\
& A=87,077 C-130.11
\end{aligned}
$$

where $\mathrm{A}$ is the area showed in $\mathrm{mAu}$ and $\mathrm{C}$ is the concentration showed in $\mathrm{g} / \mathrm{mL}$. The correlation coefficient (R2) was 0.9999 for both standardization curvatures. All the tests were performed in triplicate to have uniform results. HPLC chromatograms of the extract attained for two variations studied are shown in Figure 1.

\subsection{Acute Oral Toxicity Dose Test}

The acute oral toxicity of the extract was evaluated in 12 rabbits. They were divided into 3 groups and each group contained 4 rabbits and they were kept on fasting for $24 \mathrm{~h}$ and dosed in the following manner 500, 1000 and $2000 \mathrm{mg} / \mathrm{kg}$ body weight. After the dosing, the rabbits had been noticed for 14 days for lethargy, jerkiness, and death [30].

\subsection{Determination of DPPH Assay}

DPPH assay was conducted as described by using the previously described method [31]. In short, different concentrations of $J$. sambac extract $(4 \mathrm{~mL})$ was added to DPPH solution and prepared up to $5 \mathrm{~mL}$ with methanol, incubated for $40 \mathrm{~min}$ in dark. The spectrophotometer was used to measure the absorbance of the incubated solution at $517 \mathrm{~nm}$. All of the tests were carried out in triplicate, and the percent inhibition was measured in ascorbic acid equivalents. The DPPH scavenging effect is calculated as:

$$
1 \%=\mathrm{A}(\text { blank })-\mathrm{B}(\text { sample }) / \mathrm{A}(\text { blank }) \times 100
$$

\subsection{Acute Myocardial Infarction Study}

The animals had been divided into 4 major groups each group contained 6 rabbits. Group-1 rabbit administrated ADR $2 \mathrm{mg} / \mathrm{kg}$ body weight, subcutaneously at $24 \mathrm{~h}$ of a gap for two successive days. Group-2 rabbits were pre-treated with $100 \mathrm{mg} / \mathrm{kg}$ of extract for the period of fourteen successive days and, adrenaline $2 \mathrm{mg} / \mathrm{kg}$, was administrated on the 14th and 15th day at a gap of $24 \mathrm{~h}$. The rabbits of group-3 were pre-treated with $200 \mathrm{mg} / \mathrm{kg}$ of extract for fourteen days consecutively and on the 14th and 15th-day adrenaline $2 \mathrm{mg} / \mathrm{kg}$ was administrated subcutaneously at a gap of $24 \mathrm{~h}$. Group- 4 rabbits were pre-treated with extract in an amount of $300 \mathrm{mg} / \mathrm{kg}$ for fourteen days successively and on the 14th and 15th-day, ADR $2 \mathrm{mg} / \mathrm{kg}$ was inoculated subcutaneously at an interval of $24 \mathrm{~h}$ while 
J. sambac doses were administered via oral gavages [32]. The three doses were selected based on previously reported data on the hepatoprotective potential of the J. sambac [33]. On 16th day, rabbits were anaesthetized, and the blood samples of rabbits taken from the marginal ear vein of the rabbits to assess the biochemical parameters, including CK-MB, $\mathrm{LDH}$, troponin, CRP, ALT, AST, and ALP levels in serum, were measured by commercially available Kits.

Screening of Cardiac to Body Weight and Cardiac Weight to Tail Length Ratio

Cardiac weight and tail length were screened by measurement of cardiac weight to body weight help to key out cardiac weight index, the tail index was assessed by segmenting heart weight by tail length [6].

\subsection{Histopathology}

Rabbits had been killed under intense anaesthesia and the heart was isolated for histopathological examination, then the ventricular portion of the heart swiftly transferred to a $10 \%$ formalin solution. After that tissue had been submerged in the paraffin. A $5 \mu \mathrm{m}$ thick segment had been cut and stained with a hematoxylin-eosin dye then mounted in the xylene [34]. Microscopic observation of the ventricular portion of the heart tissues from different groups was used to evaluate the adrenaline effect on the cardiac cells structure as well as its variation by the drug test inoculation under a compound microscope and micro-images were captured.

\subsection{Isolated Aortic Tissue Preparation and Vasorelaxant Activity}

Thorax cavity was opened, and carefully aorta was dissected out after slaughtering the rabbits. Fat and connective tissues were carefully detached from the aorta in a Petri dish containing Krebs' solution. Aortic rings of 3-4 mm in length was cut and placed in tissue organ bath $(10 \mathrm{~mL})$ already contained the Krebs-Henseleit solution which is connected with thermocycler to maintain $37^{\circ} \mathrm{C}$ and continuously bubbled with carbenogen gas (95\% $\mathrm{O}_{2}$ and $5 \% \mathrm{CO}_{2}$ ). One of the hooks was fixed to the bottom, and the other was connected to a force displacement transducer that connected to a Powerlab data acquisition system to record the isometric contractions. Kreb'ssolution was changed every 15 min to prevent the buildup of metabolites throughout the $40-\mathrm{min}$ stabilization period at $1.0 \mathrm{~g}$ resting tension. After equilibration, the rings were preconstricted with $1 \times 10^{-6} \mathrm{M}$ phenylephrine (PE) until the steady contractile curve (5-8 $\mathrm{min}$ ), and the vasodilator effect of $J$. sambac was recorded on cumulative dosing manner $[35,36]$.

\subsection{Effect on Adrenaline Induced Platelet Activation and Aggregation}

The blood samples were collected from the marginal ear vein of the rabbit and centrifuged (3000 rpm for $15 \mathrm{~min}$ ) to get platelet-rich plasma. Samples were supplemented with ADR $(2 \mu \mathrm{M})$. Impedance aggregometry was used to assess platelet aggregation and flow cytometry was used to evaluate platelet activation before and after supplementations [37]. Firstly, the effect of three different added concentrations of adrenaline on platelet aggregation was assessed $(n=5)$. Next, platelet aggregation was measured after the addition of ADR in combination with J. sambac at 100, 200 and $300 \mu \mathrm{g} / \mathrm{mL}$ concentrations $(n=5)$.

\section{Conclusions}

The hydroalcoholic leaf extract of J. sambac was seen to produce vasorelaxant/ hypotensive effect during ex-vivo study via stimulating the muscarinic receptors and/or releasing the local vasodilators NO. The cardioprotective effect of hydroalcoholic leaf extract J. sambac may be due to its variety of phytoconstituents. Pretreatment with J. sambac may refill cardiomyocytes with antioxidants, which are required for defense against the oxidative stress caused by adrenaline. However, the exact molecular mechanism of cardioprotection remains to be explored. Moreover, during phytochemical screening, tan- 
nins, flavonoids, and cardiac glycosides were discovered, which have a possible impact in cardiovascular disorders, particularly hypertension-induced ventricular hypertrophy and myocardial infarction. Conclusively, ex-vivo and in-vivo research revealed J. sambac's therapeutic potential in cardiovascular diseases.

Author Contributions: Conceptualization, M.H. and A.M.; methodology, S.A.; software, M.O.I.; validation, S.H.M.; formal analysis, W.S.; writing-original draft preparation, K.A. and M.A.S.; investigation, I.A.K.; supervision, M.H.; Review and writing, S.K.S. All authors have read and agreed to the published version of the manuscript.

Funding: This is part of Ph.D. thesis of first autholr and received no funding from any funding agency.

Institutional Review Board Statement: The study was conducted according to the guidelines of the National institute of Health, 2005 and approved by the Institutional Review Board (or Ethics Committee) of Department of Pharmacology, The Islamia University of Bahawalpur (BOS \& BOF/10/6/20.

Informed Consent Statement: Not applicable.

Data Availability Statement: Not applicable.

Acknowledgments: Authors are thankful to Qaisar Jabeen, Chairperson Department of Pharmacology for her administrative and technical support.

Conflicts of Interest: The authors declare no conflict of interest.

Sample Availability: Samples of the compounds are available from the authors.

\section{References}

1. Khan, I.A. Pharmacotherapeutic modifications in cardiopulmonary patients during COVID-19 outbreak. J. Coll. Phy. Surg. Pak. 2020, 30, 15-17.

2. Quiñones, M.; Miguel, M.; Aleixandre, G. Beneficial effects of polyphenols on cardiovascular disease. Pharmacol. Res. 2013, 68, 125-131. [CrossRef]

3. Shaito, A.; Thuan, D.T.B.; Nguyen, T.H.D.; Hasan, H.; Halabi, S.; Abdelhady, S.; Nasrallah, G.K.; Pintus, G. Herbal Medicine for Cardiovascular Diseases: Efficacy, Mechanisms, and Safety. Front. Pharmacol. 2020, 11, 422. [CrossRef]

4. Kumar, S.V.; Saritha, G.; Fareedullah, G. Role of antioxidants and oxidative stress in cardiovascular diseases. Ann. Biol. Res. 2010, 3, 158-173.

5. Tsoupras, A.; Lordan, R.; Zabetakis, I. Inflammation, not Cholesterol, Is a Cause of Chronic Disease. Nutrients 2018, 10, 604. [CrossRef]

6. Amin, M.M.; El-Gazayerly, O.N.; Gawad, N.A.; Halim, S.M. Effect of formulation variables on design, in vitro evaluation of valsartan SNEDDS and estimation of its antioxidant effect in adrenaline-induced acute myocardial infarction in rats. Pharmaceut. Dev. Technol. 2016, 21, 909-920. [CrossRef]

7. Fathiazad, F.; Matlobi, S.; Khorrami, N. Phytochemical screening and evaluation of cardioprotective activity of ethanolic extract of Ocimumbasilicum L. (basil) against isoproterenol induced myocardial infarction in rats. DARU J. Pharma. Sci. 2012, 20, 198-203.

8. Saqib, F.; Arif Aslam, M.; Mujahid, K.; Marceanu, L.; Moga, M.; Ahmedah, H.T.; Chicea, L. Studies to Elucidate the Mechanism of Cardio Protective and Hypotensive Activities of Anogeissus acuminata (Roxb. ex DC.) in Rodents. Molecules 2020, $25,3471$. [CrossRef] [PubMed]

9. Koffuor, G.A.; Amoateng, P. Anti-oxidant and anticoagulant properties of Phyllanthus fraternus GL webster (Family: Euphorbiaceae). J. Pharmacol. Toxicol. 2012, 6, 624-626. [CrossRef]

10. Khare, C.P. Encyclopedia of Indian Medicinal Plants, Rational Western Therapy. Ayurvedic and Other Traditional Usage, Botany; Springer Publications: Berlin/Heidelberg, Germany, 2004; pp. 314-315.

11. Al-Snafi, A.E. Pharmacological and therapeutic effects of Jasminum sambac-A review. Indo Am. J. Pharma. Sci. 2018, 5, 1766-1778.

12. Phanukit, K.U.; Chuleratana, B.; Kajsongkram, T.; Amonrat, K.H. Chemical composition, toxicity and vasodilatation Effect of the flowers extract of Jasminum sambac (L.) Ait. "G. Duke of Tuscany". Evid.-Based Complement. Altern. Med. 2012, 47, $1312-1317$.

13. Bucki, R.; Pastore, J.J.; Giraud, F.; Sulpice, J.C.; Janmey, P.A. Flavonoid inhibition of platelet procoagulant activity and phosphoinositide synthesis. J. Thromb. Haemost. 2003, 1, 1820-1828. [CrossRef] [PubMed]

14. Kumari, G.; Wong, K.U.; Serr, A.; Joon, S.; Yoon, S.H.; Tam, P. Molecular diversity and function of jasmintides from Jasminum sambac. BMC Plant. Biol. 2018, 18, 144-149. [CrossRef] [PubMed]

15. Dong, Y.; Duan, L.; Chen, H.W.; Liu, Y.M.; Zhang, Y. Network pharmacology-based prediction and verification of the targets and mechanism for Panax notoginseng saponins against coronary heart disease. Evid.-Based Complement. Altern. Med. 2019, 65, 37-52. [CrossRef] [PubMed] 
16. He, Y.; Hu, Z.; Li, A.; Zhu, Z.; Yang, N.; Ying, Z. Recent advances in biotransformation of saponins. Molecules 2019, $24,2365$. [CrossRef]

17. Sun, J.; Yu, X.; Huangpu, H.; Yao, F. Ginsenoside Rb3 protects cardiomyocytes against hypoxia/reoxygenation injury via activating the antioxidation signaling pathway of PERK/Nrf2/HMOX1. Biomed. Pharmacother. 2019, 109, 254-261. [CrossRef]

18. Mundugaru, R.; Udaykumar, P.; Senthilkumar, S.; Bhat, S. Cardioprotective activity of fruit of Garcinia pedunculata on isoprenalineinduced myocardial infarction in rat. Bangladesh J. Pharmacol. 2018, 11, 231-235. [CrossRef]

19. Kalaiselvi, M.; Narmadha, R.; Ragavendran, P.; Arul, R.; Sophia, D.; Ravi, K.G.; Gomathi, D.; Uma, C. In vivo simulated in vitro model of Jasminum sambac Linn. using mammalian liver slice technique. Asian Pac. J. Trop. Biomed. 2011, 16, 216-219. [CrossRef]

20. Ittagi, S.; Merugumolu, K.M.; Siddamsetty, S.K. Cardioprotective effect of hydroalcoholic extract of Tecoma stans flowers against isoproterenol induced myocardial infarction in rats. Asian Pac. J. Trop. Biomed. 2014, 4, S378-S384. [CrossRef]

21. Panchal, S.K.; Brown, L. Cholesterol versus Inflammation as Cause of Chronic Diseases. Nutrients 2019, 11, 2332. [CrossRef]

22. Gilani, A.H.; Janbaz, K.H.; Zaman, H.; Lateef, A.; Suria, A. Possible Presence of Calcium Channel Blocker(s) in Rubia cordifolia: An Indigenous Medicinal Plant. JPMA 1994, 44, 84-89.

23. Prince, P.S.; Rajakumar, S.; Dhanasekar, K. Protective effects of vanillic acid on electrocardiogram, lipid peroxidation, antioxidants, proinflammatory markers and histopathology in isoproterenol induced cardiotoxic rats. Eur. J. Pharmacol. 2011, 668, 233-240. [CrossRef]

24. Wang, X.L. Potential herb-drug interaction in the prevention of cardiovascular diseases during integrated traditional and western medicine treatment. Chin. J. Integr. Med. 2015, 21, 3-9. [CrossRef]

25. Satoh, S.; Nishida, S. Electropharmacological actions of Ginkgo biloba extract on vascular smooth and heart muscles. Clin. Chim. Acta 2004, 342, 13-22. [CrossRef] [PubMed]

26. Khan, I.A.; Lodhi, A.H.; Munawar, S.H.; Manzoor, A.; Manzoor, Z.; Raza, M.A.; Iqbal, O. Assessment of ameliorative effect of Aab-e-Shifa polyherbal formulation in experimentally-induced wound in rabbits. Trop. J. Pharm. Res. 2020, 19, $2357-2362$.

27. National Institute of Health. Guide for the Care and Use of Laboratory Animals; No. 85-23; NIH Publication: Bethesda, MD, USA, 1985.

28. Trease, G.E.; Evans, W.C. Trease and Evans' Pharmacognosy, 16th ed.; Saunders/Elsevier: Edinburgh, Australia, 2009.

29. Teresa, F.M.; Lourdes, C.; Mantell, C.; Miguel, R.; Enrique, M.O. Extraction of antioxidant compounds from different varieties of Mangifera indica leaves using green technologies. J. Sup. Fluids 2012, 72, 168-175.

30. Al-Afifi, N.A.; Alabsi, A.M.; Bakri, M.M. Acute and sub-acute oral toxicity of Dracaena cinnabari resin methanol extract in rats. BMC Complement. Altern. Med. 2018, 18, 50-55. [CrossRef] [PubMed]

31. Sreejayan, A.; Rao, M.N. Free radicals scavenging activity of curcuminoids. Drug Res. 1996, 46, 169-173.

32. Salma, A.; El-Marasy, S.A.; Awdan, E.; Hassan, H.; Heba, M.I. Cardioprotective effect of thymol against adrenaline-induced myocardial injury in rats. Heliyon 2020, 7, 35-39.

33. Veeresh, B.D.; Ramesh, K.; Bhatt, K. Evaluation of Hepatoprotective activity of Jasminum sambac in rats. Int. J. Res. Pharmacol. Pharmacother. 2017, 6, 104-116.

34. Khan, I.A.; Lodhi, A.H.; Munawar, S.H.; Manzoor, A.; Manzoor, Z.; Raza, M.A. Formulation and evaluation of allicin and curcumin gel improves normal and diabetic ulcers in rabbits. Lat. Am. J. Pharm. 2018, 37, 1602-1607.

35. Imtiaz, S.M.; Aleem, A.; Saqib, F.; Ormenisan, A.N.; Elena Neculau, A.; Anastasiu, C.V. The Potential involvement of an ATP-Dependent Potassium Channel-Opening Mechanism in the Smooth Muscle Relaxant Properties of Tamarix dioica Roxb. Biomolecules 2019, 9, 722. [CrossRef] [PubMed]

36. Isik, B.S.; Altay, F.; Capanoglu, E. The uniaxial and coaxial encapsulations of sour cherry (Prunus cerasus L.) concentrate by electrospinning and their in vitro bioaccessibility. Food Chem. 2018, 265, 260-273. [CrossRef] [PubMed]

37. Singh, S.; Malm, C.J.; Ramström, S.; Hesse, C.; Jeppsson, A. Adrenaline enhances in vitro platelet activation and aggregation in blood samples from ticagrelor-treated patients. Res. Pract. Thromb. Haemost. 2018, 2, 718-725. [CrossRef] [PubMed] 